East African Medical Journal Vol. 77 No. 3 March 2000

TANZANIAN HIGH SCHOOL STUDENTS' ATTITUDE TOWARDS FIVE UNIVERSITY PROFESSIONAL COURSES

E.N. Kikwilu, DDS (Dar), MDent (Dar), Lecturer, E.A. Mugonzibwa, DDS (Dar), Assistant Lecturer, P.G.N. Rugarabamu, DDS (Dar), MDent (Dar), Lecturer, Department of Preventive and Community Dentistry, Faculty of Dentistry, Muhimbili University College of Health Sciences, University of Dar es Salaam, P.O. Box 65014, Dar es Salaam, Tanzania and M.K. Ntabaye, DDS (Dar), PhD (Aarhus), Training Officer, Central Oral Health Unit, Ministry of Health, Tanzania, P.O. Box 275, Dar es Salaam, Tanzania

Request for reprints to: Dr. E.N. Kikwilu, Faculty of Dentistry, Muhimbili University College of Health Sciences, P.O. Box 65014, Dar es Salaam, Tanzania.

\title{
TANZANIAN HIGH SCHOOL STUDENTS' ATTITUDE TOWARDS FIVE UNIVERSITY PROFESSIONAL COURSES
}

\author{
E.N. KIKWILU, E.A. MUGONZIBWA, P.G.N. RUGARABAMU and M.K. NTABAYE
}

\begin{abstract}
Objective: To determine the attitude of high school students majoring in Physics, Chemistry and Biology (PCB) towards Medicine, Pharmacy, Dentistry, Veterinary Medicine and Nursing as professions at university.

Design: A cross sectional study of a representative sample of high school students using a pretested attitudinal questionnaire. Attitude components tested were degree of liking, degree of admiration and intentions to visit a professional at work.

Setting: High schools in Tanzania mainland majoring in PCB.

Subjects and Methods: All 352 high school students from a representative sample of five schools: two boy-schools; two girl-schools; and one mixed gender-school participated by filling in a questionnaire. The questionnaire consisted of demographic variables on age, sex, class, education and employment status of father and mother as background variables, and questions on the degree of liking, admiration and preference to visit a particular professional at work. All the attitudinal questions were scored on a 5-point scale. Scores for the threeattitudinal components were summed to group subjects into positive, neutral and negative attitude.

Main outcome measure: Attitude of students to five professions they could study at a higher level.

Results: Eighty seven percent of the high school students had a positive attitude towards medicine, $66 \%$ towards pharmacy, $40 \%$ dentistry, $12 \%$ veterinary and $9 \%$ nursing. Dentistry and veterinary had the highest percentage of students $(46.5 \%$ and $37.3 \%)$ who had a neutral attitude towards the professions, and the highest percentage of students $(11.7 \%$ and 9.9\%) who reported to have had no sufficient information to enable them indicate whether they admired dentistry and veterinary medicine or not. Significantly more girls than boys liked, admired and preferred to study nursing ( $\chi 2$ varied from 11.39 to 12.99; p-value $<0.005$ ).

Conclusion: Medicine was the most liked profession while nursing was the least liked. Pharmacy, dentistry and veterinary medicine fell in between. There was insufficient knowledge about dentistry and veterinary medicine among the high school students.
\end{abstract}

\section{INTRODUCTION}

An attitude towards any concept/object is simply a person's general feeling of favourableness or unfavourableness for that concept/object. It is an index of the degree to which a person likes or dislikes an object. A person's attitude towards the object has been shown to have influence on the overall pattern of his/her response to the object but that need not predict any actions. Studying attitudes of potential applicants toward the courses that they can study at University level is particularly important because i) schools or faculties that compete for recruitment of applicants with the same qualifications and background can utilise this information for the advertisement of their courses, ii) the same information can also help to identify the relative importance and position of these professions in the eyes of potential applicants. This may trigger the need to identify and address the potential negative features of a profession identified as less preferred.

In Tanzania, most applicants for places in institutions of higher learning are A-level secondary school-leavers. A-level secondary school education is categorised into science and arts/social science subjects. Students in schools offering sciences have to study one of the following 
combinations of three principal subjects i.e. Physics, Chemistry and Biology (PCB), Physics, Chemistry and Mathematics (PCM); Physics, Geography and Mathematics (PGM) and Chemistry, Biology and Geography (CBG). These combinations of subjects narrow the choice of the students for a future career. For example, there are six-degree courses to which a student with PCB A-level background can apply. Despite this narrowing, there is still competition for applicants to these courses hence some get fewer applicants than others. In this way, dentistry and nursing have been getting few qualified applicants for enrollment. Courses that get adequate qualified applicants are Medicine, Pharmacy and Veterinary medicine. Kuusela and her colleagues studied career choice among 25 dental students who were enrolled with the Faculty of Dentistry in Dar es Salaam. Only one student (4\%) had dentistry as first choice. Whereas for Kuopio dental students studied in the same year, 34\% had dentistry as their first choice(2). Studies in Kenya $(3,4)$ and India(5) also showed that applicants in these countries preferred studying medicine or pharmacy to dentistry. This is shown by the fact that $61-71 \%$ of dental students had dentistry as their second choice. Medicine and Pharmacy were their first choices. Among Indian women who joined dentistry in 1994, thirty-six (36\%) had dentistry as their first choice(6). In developed countries the proportion of dental students who take dentistry as first choice seems to be higher than in developing countries. In mid 1970s most applicants for dentistry (88\%) had dentistry as their first choice in USA(7). Morris in 1992 reported $68 \%$ of the first year dental students in UK to had picked dentistry as their first career of choice before A-level examination results. After the results the proportion of students who had dentistry as their first choice rose to $88 \%$ (8). This preference may be of little or no concern when the number of qualified applicants satisfies all the competing courses. On the contrary, if qualified applicants are less than the required number, the less preferred courses suffer, and the need to advertise the less preferred courses arises.

The Faculty of Dentistry in Dar es Salaam, Tanzania, would like to embark on advertising its course in view of raising the number of qualified applicants. In order to have a sound advertising background, information on the attitude of potential applicants towards courses that compete for applicants with dentistry needs to be investigated. The aim of this study was to evaluate the attitude of students in high schools with the PCB subject combination towards the five-degree courses that are offered for study at University.

\section{MATERIALS AND METHODS}

Subjects: Students studying in five randomly selected high schools majoring in Physics, Chemistry and Biology in AugustSeptember 1997. There are 34 high schools in Tanzania mainland whose major subjects are Physics, Chemistry and Biology. These were stratified into three strata based on whether they were purely boys, or girls or mixed gender schools. A 10\% random sample of schools from each stratum was selected using random numbers. This resulted in a sample of five schools: two boyschools, two girl-schools and one mixed gender-school. A total of 352 students who were present in their respective classes during the time of administration of the questionnaire participated in the study.

Instruments: This report is part of the main study that explored factors influencing career choice among potential applicants for dentistry in Tanzania. The attitudinal part of the questionnaire explored on how subjects liked a given profession, the order the respondent would have preferred if given a chance to visit and observe each of the professionals at work, and the degree to which the respondent was attracted by a given profession or admired it. Both items were scaled and scored using 5 points, e.g. from most liked to most disliked profession. Demographic information of respondents with particular attention to the gender of the respondent and education and employment status of the parents were also recorded. A pre-tested questionnaire was administered to students who were in classes during the time of the study. After permission had been sought from the education and school authorities, students, while in class were requested to fill in a questionnaire in the presence of a researcher who visited the school. A researcher was introduced as having come from Muhimbili University College of Health Sciences, without disclosing the faculty he/she belonged to.

Analysis: Frequencies were generated for the 5-point scale, and later the scale was collapsed to three categories representing liked, neutral and disliked, or admired, neutral, not admired. The three categories were then compared with background variables: school, gender, education and employment status of parents. $\chi 2$ test was used to detect differences between background variables. Only the gender showed a statistically significant difference. Therefore, the results on outcome variables are summarised by gender. An attitude score was computed by summing the scores for the three variables used to measure attitude i.e. degree of liking, admiration and preference. The highest score for the attitude was 15 , and the lowest score was 3 . Subjects scoring 7 and below were categorised as having unfavourable attitudes; those with a score 8 to 10 were categorised as having a neutral attitude, and those scoring 11 to 15 were categorised as having favourable attitude. Frequency distribution of the subjects for the three categories was generated.

\section{RESULTS}

A total of 352 students (181 boys, 171 girls) aged 17 - 27 years (mode $=20$ yrs) participated in the study. Fifty four percent of the students' mothers and $72 \%$ of fathers had at least an ordinary level secondary education. Sixty three percent of the fathers and $49 \%$ of the mothers were office employees.

Table 1 shows the percentage distribution of the respondents according to how they liked the professions by gender. Medicine was the most liked profession both by boys $(89.8 \%)$ and girls $(90.4 \%)$. Pharmacy was the second most liked profession ( $71.1 \%$ for boys, $72.6 \%$ for girls), dentistry ( $50.0 \%$ for boys, $41.3 \%$ for girls), veterinary ( $18.9 \%$ for boys, $16.3 \%$ for girls). Nursing was the least liked profession with only $6.2 \%$ for boys and $10.0 \%$ for girls. More girls than boys indicated that they liked nursing $(\chi 2=11.39, \mathrm{p}=0.003)$. Dentistry had the highest proportion $(32.9 \%)$ of respondents who neither liked nor disliked It. Nursing had the highest proportion $(81.6 \%)$ of respondents who disliked it. 
Table 1

Percent distribution of 352 subjects according to how they like the professions

\begin{tabular}{|c|c|c|c|c|c|}
\hline \multirow[t]{2}{*}{ Profession } & \multicolumn{3}{|c|}{ Degree of liking } & \multirow[t]{2}{*}{$\chi^{2}$} & \multirow[t]{2}{*}{$\mathrm{p}$-value } \\
\hline & Like & Neutral & Dislike & & \\
\hline \multicolumn{6}{|l|}{ Medicine } \\
\hline Boys & 89.8 & 8.5 & 1.7 & & \\
\hline Girls & 90.4 & 7.8 & 1.8 & Not valid & \\
\hline Total & 90.1 & 8.1 & 1.7 & & \\
\hline \multicolumn{6}{|l|}{ Pharmacy } \\
\hline Boys & 71.1 & 17.2 & 11.7 & & \\
\hline Girls & 726 & 17.9 & 9.5 & 0.42 & 08.09 \\
\hline Total & 71.8 & 17.5 & 10.6 & & \\
\hline \multicolumn{6}{|l|}{ Dentistry } \\
\hline Boys & 50.0 & 33.0 & 17.0 & & \\
\hline Girls & 413 & 32.9 & 25.8 & 4.46 & 0.107 \\
\hline Total & 45.8 & 32.9 & 21.3 & & \\
\hline \multicolumn{6}{|l|}{ Veterinary } \\
\hline Boys & 18.9 & 31.4 & 49.7 & & \\
\hline Girls & 16.3 & 24.1 & 59.6 & 3.51 & 0.173 \\
\hline Total & 17.6 & 27.9 & 54.5 & & \\
\hline \multicolumn{6}{|l|}{ Nursing } \\
\hline Boys & 6.2 & 5.6 & 88.2 & & \\
\hline Girls & 10.0 & 15.3 & 74.7 & 11.39 & $0.003 * *$ \\
\hline Total & 8.1 & 10.3 & 81.6 & & \\
\hline
\end{tabular}

** Significant at $1 \%$ level.

Table 2 shows the distribution by gender of respondents according to the preference to visit and observe a particular professional at work. Most boys (84.9\%) and girls $(83.9 \%)$ would have liked to visit and observe a doctor of medicine performing his/her work. Sixty-one percent of boys and $65.5 \%$ of girls would have preferred visiting and observing a Pharmacist at work. Dentistry scored $36.2 \%$ and $29.5 \%$ for boys and girls respectively.

Nursing scored the least with $6.6 . \%$ and $10.1 \%$ of all boys and girls respectively. More girls than boys indicated
Table 2

Percent distribution of 352 respondents according to how they prefer to visit a professional artwork

\begin{tabular}{|c|c|c|c|c|c|}
\hline \multirow[t]{2}{*}{ Profession } & \multicolumn{3}{|c|}{ Degree of preference } & \multirow[t]{2}{*}{$\chi^{2}$} & \multirow[t]{2}{*}{ p-value } \\
\hline & Prefer & Neutral & Not prefered & & \\
\hline \multicolumn{6}{|l|}{ Medicine } \\
\hline Boys & 89.8 & 8.5 & 1.7 & \multirow{3}{*}{\multicolumn{2}{|c|}{ Not valid }} \\
\hline Girls & 90.4 & 7.8 & 1.8 & & \\
\hline Total & 90.1 & 8.1 & 1.7 & & \\
\hline \multicolumn{6}{|l|}{ Pharmacy } \\
\hline Boys & 71.1 & 17.2 & 11.7 & \multirow{3}{*}{0.42} & \multirow{3}{*}{08.09} \\
\hline Girls & 72.6 & 17.9 & 9.5 & & \\
\hline Total & 71.8 & 17.5 & 10.6 & & \\
\hline \multicolumn{6}{|l|}{ Dentistry } \\
\hline Boys & 50.0 & 33.0 & 17.0 & \multirow{3}{*}{4.46} & \multirow{3}{*}{0.107} \\
\hline Girls & 41.3 & 32.9 & 25.8 & & \\
\hline Total & 45.8 & 32.9 & 21.3 & & \\
\hline \multicolumn{6}{|l|}{ Veterinary } \\
\hline Boys & 18.9 & 31.4 & 49.7 & \multirow{3}{*}{3.51} & \multirow{3}{*}{0.173} \\
\hline Girls & 16.3 & 24.1 & 59.6 & & \\
\hline Total & 17.6 & 27.9 & 545 & & \\
\hline \multicolumn{6}{|l|}{ Nursing } \\
\hline Boys & 6.2 & 5.6 & 88.2 & \multirow{3}{*}{11.39} & \multirow{3}{*}{$0.003_{*}$} \\
\hline Girls & 10.0 & 15.3 & 74.7 & & \\
\hline Total & 8.1 & 10.3 & 81.6 & & \\
\hline
\end{tabular}

** Significant at $1 \%$ level.

that they would have preferred to visit and observe a nurse at work $(\chi 2=11.32, \mathrm{p}=0.003)$. Dentistry had the highest proportion (40.1\% for boys, $39.8 \%$ for girls) of respondents who neither preferred nor disliked it. Nursing had the highest proportion ( $88.0 \%$ for boys, $74.4 \%$ for girls) of respondents who would not have preferred to visit and observe a nurse at work.

The proportion of respondents according to how they were attracted to a profession or admired it is shown in Table 3. Seventy-eight percent of boys and $77.6 \%$ of girls

Table 3

Percent distribution of 352 subjects according to how they admired the professions

\begin{tabular}{|c|c|c|c|c|c|c|}
\hline \multirow[t]{2}{*}{ Profession } & \multicolumn{4}{|c|}{ Degree of admiration } & \multirow[t]{2}{*}{$\chi 2$} & \multirow[t]{2}{*}{ p-value } \\
\hline & Admire & Neutral & $\begin{array}{l}\text { Do not } \\
\text { admire }\end{array}$ & $\begin{array}{l}\text { No sufficient information } \\
\text { to make judgement }\end{array}$ & & \\
\hline \multicolumn{7}{|l|}{ Medicine } \\
\hline Boys & 78.5 & 18.8 & 2.2 & 05 & \multirow{3}{*}{0.19} & \multirow{3}{*}{0.9785} \\
\hline Girls & 776 & 8.8 & 3.0 & 0.6 & & \\
\hline Total & 780 & 8.8 & 2.6 & 0.6 & & \\
\hline \multicolumn{7}{|l|}{ Pharmacy } \\
\hline Boys & 59.9 & 28.6 & 9.9 & 1.6 & \multirow{3}{*}{ Not valid } & \\
\hline Girls & 649 & 226 & 9.5 & 3.0 & & \\
\hline Total & 62.3 & 25.7 & 97 & 2.3 & & \\
\hline \multicolumn{7}{|l|}{ Dentistry } \\
\hline Boys & 32.6 & 42.5 & 13.8 & 11.1 & \multirow{3}{*}{4.83} & \multirow{3}{*}{0.184} \\
\hline Girls & 225 & 468 & 18.3 & 12.4 & & \\
\hline Total & 27.7 & 44.6 & 16.0 & 11.7 & & \\
\hline \multicolumn{7}{|l|}{ Veterinary } \\
\hline Boys & 16.5 & 30.8 & 42.3 & 10.4 & \multirow{3}{*}{1.62} & \multirow{3}{*}{0.655} \\
\hline Girls & 159 & 71 & 37.6 & 9.4 & & \\
\hline Total & 162 & 3.8 & 40.1 & 9.9 & & \\
\hline \multicolumn{7}{|l|}{ Nursing } \\
\hline Boys & 12.2 & 29.8 & 50.3 & 7.7 & \multirow{3}{*}{12.99} & \multirow{3}{*}{$0.005^{* *}$} \\
\hline Girls & 172 & 5.5 & 46.7 & 0.6 & & \\
\hline Tota1 & 14.6 & 2.6 & 48.6 & 4.2 & & \\
\hline
\end{tabular}

\footnotetext{
** Significant at $1 \%$ level.
} 
reported to have admired medicine. About $60 \%$ of the boys and $64.9 \%$ of the girls admired pharmacy, $32.6 \%$ and $22.5 \%$ of boys and girls respectively admired dentistry. Veterinary and nursing scored the least. Dentistry had the highest proportion of the respondents $(42.5 \%$ of boys, $46.8 \%$ of girls) who were neutral in admiration and highest proportion of respondents ( $11.1 \%$ of boys, $12.4 \%$ of girls) who had insufficient information to rate their admiration. Only $0.6 \%$ reported to have had insufficient information about medicine to tell whether they admired it or not. About a third of the respondents had neutral admiration in nursing, and more girls than boys reported to have admired nursing $(\chi 2=12.99, \mathrm{p}=0.005)$. About $8 \%$ of the boys and $0.6 \%$ of the girls reported to have had insufficient information to rate their admiration in nursing.

Table 4

Percent distribution of 352 subjects into three attitudinal categories for each profession

\begin{tabular}{lccc}
\hline \multirow{2}{*}{ Profession } & \multicolumn{3}{c}{ Attitude towards a profession } \\
& Favourable & Neutral & Unfavourable \\
\hline Medicine & 87.3 & 11.8 & 0.9 \\
Pharmacy & 66.1 & 24.7 & 9.1 \\
Dentistry & 40.2 & 46.5 & 13.3 \\
Veterinary & 12.1 & 37.3 & 50.6 \\
Nursing & 9.3 & 26.5 & 64.2 \\
\hline
\end{tabular}

Table 4 shows the distribution of respondents according to the attitude categories. Most respondents had positive or favourable attitudes towards medicine and pharmacy. Over sixty percent of the respondents had unfavourable attitudes towards nursing. Other professions fell in between.

\section{DISCUSSION}

The age of respondents correspond well with the expected age for high school students in Tanzania. The age of entry in primary school is seven years. Therefore most students in high schools will be about the age of $19-20$ years. The educational background and employment status for parents of the respondents show that children who manage to attain high school education mainly come from the families of educated parents in office employment or business. Only a few children of peasants and less educated families get this opportunity.

This pathfinder study aimed at assessing the degree to which the potential applicants for dentistry like, prefer and admire the five professions that they could study at university. These findings show that medicine was the most liked, admired and preferred profession compared to others. Pharmacy was the second followed by dentistry, veterinary medicine and nursing respectively. Likewise, the attitudinal score showed that medicine was the most favoured profession and nursing being the least favoured. This reflects the picture observed during selection of MUCHS students whereby most applicants apply for admission into medicine and pharmacy courses. Dentistry is considered third while nursing usually gets the least applicants.
Forty six percent of respondents were classified as having had a neutral attitude towards dentistry. This may indicate that dentistry is not well known by the population studied. This is supported by the relatively high proportion $(11.7 \%)$ of respondents compared to medicine $(0.5 \%)$ who reported to have had insufficient information to say whether they admired dentistry or not (Table 3). Insufficient knowledge about dentistry at the time of applying for dentistry was also reported as high among Nairobi Dental students(4). This finding indicates the need for the Faculty of Dentistry to popularise its course to the potential applicants.

The introduction of researchers who collected data from schools as coming from MUCHS may have introduced the bias in favour of MUCHS courses against veterinary medicine. Furthermore the researchers were identified as doctors from MUCHS. This may also have led respondents to incline more towards the doctor of medicine. Nevertheless, the findings present the same picture as that reported in other studies done in Nairobi(4) and India(5). Since the study population was randomly selected and consisted of ten percent of the target population, thus representative of the target population, it can be inferred that PCB students in Tanzania prefer, admire and like medicine and pharmacy more than dentistry, veterinary and nursing. It is therefore recommended that a study be designed to identify beliefs that determine the attitude of PCB students towards these five professions in order to identify areas of intervention.

\section{ACKNOWLEDGEMENTS}

The authors thank Muhimbili University College of Health Sciences (MUCHS) and Swedish Agency for Research Co-operation with Developing Countries (SAREC) for funding this study.

\section{REFERENCES}

1. I. Ajzen and M. Fishbein. Understanding attitudes and predicting social behaviour. PrenticeHall, New Jersey. 1980.

2. S. Kuusela, E. Honkala, H. Hausen, D., Rwakatema, I. and Guya M. Lampiranta. Opinion of dental students in Dar es Salaam (Tanzania) and in Kuopio (Finland) concerning studies and expectations for future career. African Dent. J. 1993; 7: 20-6.

3. A.W. Murrithi and M.L. Chindia. Analysis of factors influencing choice of dentistry as a career among dental students in Kenya. IADR East and Southern Africa Section Conference, 1990. ABSTMCT.

4. A.W. Murrithi and M.L. Chindia. Attitudes of University of Nairobi Dental Students towards their career. 12th Annual Scientific Conference of the East and Southern Africa Division of the International Association for Dental Research (IADR) 28th - 30th October 1998, Nairobi, Kenya. Programme and Abstract: Abstr. No.4.

5. A. Catthopadhyay and R.S. Deol. Reasons for choice of dentistry as a career in Calcutta: a survey report. Indian J. Dent. Res. 1990; 2: 140-4.

6. T.M. Padma, R.V. Raja and K.W. Prasad. An insight into dentistry as a career choice for women. J. Indian Dent. Assoc. 1994; 65: 202-7.

7. J.A. Coombs. Factors associated with career choice among women dental students. J. Dent. Education 1976; 40: 724-31.

8. S. Morris. What kind of people want to become dentists? General Dental Council Recruitment working party survey of first year undergraduate dental students. Brit. Dent. J. 1992; 4: 143-4. 